\title{
“Take your polyp for a walk": endoscopic retrieval of multiple colon polyps using a clip and line
}

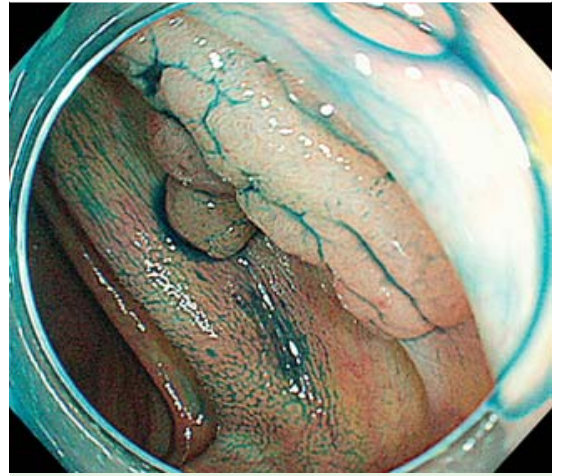

Fig. 1 Chromoendoscopic image of a large $(20 \mathrm{~mm})$ laterally spreading adenoma in the ascending colon.

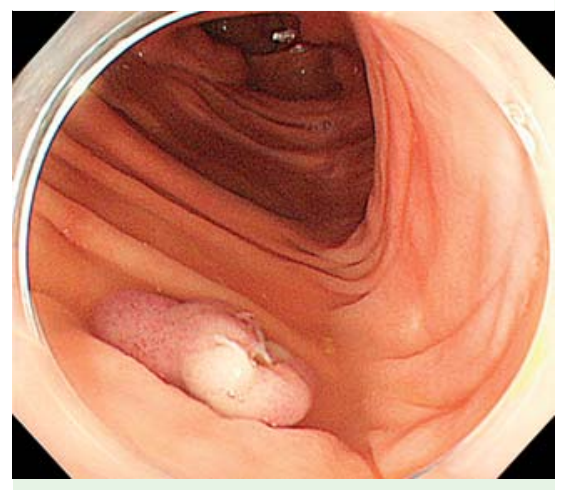

Fig. 2 The resected polyp after underwater endoscopic mucosal resection.

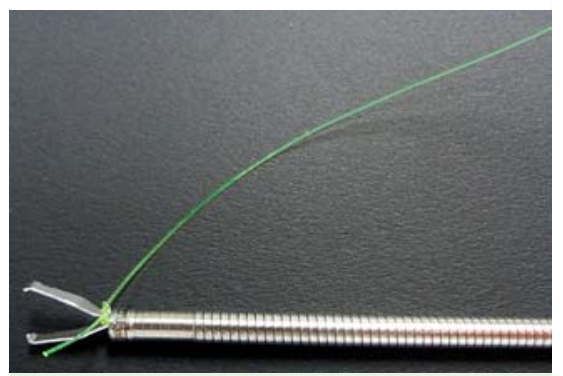

Fig.3 A nylon line tied to the teeth of an endoclip.

Detecting and removing colonic polyps reduces the incidence of colorectal cancer [1]. Small polyps can be retrieved through a working channel into a suction trap or discarded, as almost all are indolent and pathological examination is not considered to be important $[2,3]$. As large polyps $(\geq 10 \mathrm{~mm})$ may harbor invasive cancer,

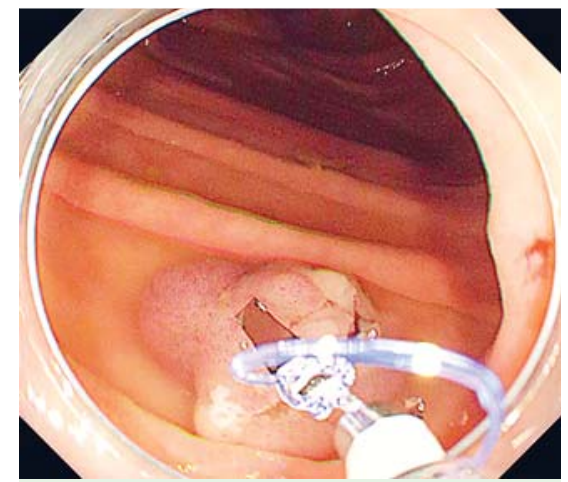

Fig.4 Application of a clip and line to a resected specimen.

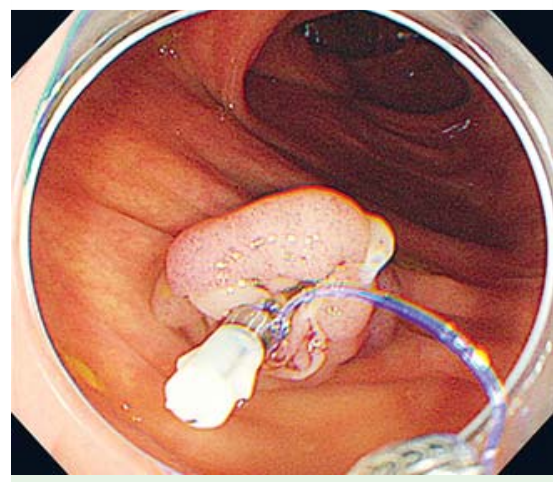

Fig. 5 A resected specimen connected to the endoscope by the clips and lines.

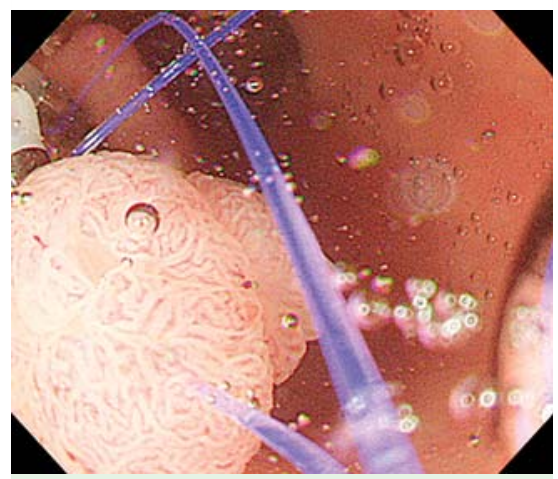

Fig. 6 Retrieval of two resected specimens using the clip and line.

they should always be retrieved and sent for careful pathological examination. During retrieval by suction or grasping, polyps may drop off and roll back into the colon or block further endoscopic view, preventing the detection of other polyps. Moreover, the number of polyps retrieved by conventional methods is lim-

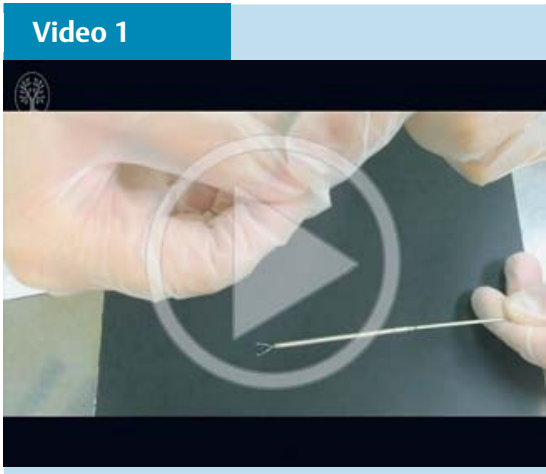

“Take your polyp for a walk": clip and line technique for retrieval of multiple large polyps after resection.

ited. This report describes a new retrieval method, using a clip and line, which does not require withdrawal and reinsertion of the colonoscope.

A 78-year-old man was referred for endoscopic resection of polyps located in the ascending and transverse colon ( $\bullet$ Fig. 1 , - Video 1). After removal of the polyp in the ascending colon ( $\bullet$ Fig. 2 ), a nylon line was attached to the teeth of an endoclip (HX-610-090; Olympus, Tokyo, Japan) ( Fig.3), as described elsewhere [4]. The endoclip was applied to the polyp ( $\bullet$ Fig.4), and the resected specimen was attached to the endoscope via the clip and line ( $\bullet$ Fig.5). The examination was continued while maintaining the distance between the resected specimen and the tip of the endoscope, so as not to impair the endoscopic view. As the channel was not blocked, it was possible to resect additional polyps, with small polyps removed by suction through the channel and large polyps held in the lumen by additional clips and lines before subsequent retrieval. A polyp in the transverse colon was removed and retrieved using the same method ( $\bullet$ Fig.6). A similar method has been described, but the clip and line were applied before polypectomy [5]. We believe that our method is simpler and more effective than this earlier method.

Endoscopy_UCTN_Code_TTT_1AQ_2AD

Competing interests: None 
Tomofumi Akasaka, Yoji Takeuchi, Yasushi Yamasaki, Noboru Hanaoka, Noriya Uedo, Ryu Ishihara, Hiroyashu lishi

Department of Gastrointestinal Oncology, Osaka Medical Center for Cancer and Cardiovascular Diseases, Osaka, Japan

\section{References}

1 Zauber AG, Winawer SJ, O'Brien MJ et al. Colonoscopic polypectomy and long-term prevention of colorectal-cancer deaths. N Engl J Med 2012; 366: 687-696

2 Ignjatovic A, East JE, Suzuki $N$ et al. Optical diagnosis of small colorectal polyps at routine colonoscopy (Detect InSpect ChAracter- ise Resect and Discard; DISCARD trial): a prospective cohort study. Lancet Oncol 2009; 10: 1171 - 1178

3 Takeuchi Y, Hanafusa M, Kanzaki H et al. An alternative option for "resect and discard" strategy, using magnifying narrow-band imaging: a prospective "proof-of-principle" study. J Gastroenterol 2015; 50: 1017-1026

4 Yamasaki Y, Takeuchi Y, Hanaoka N et al. A novel traction method using an endoclip attached to a nylon string during colonic endoscopic submucosal dissection. Endoscopy 2015; 47 (Suppl. 01): E238 - E239

5 Hashimoto Y, Toyota J, Fujii T et al. Modification of endoscopic mucosal resection to collect plural polypectomied specimens with clip connected with string using a onechannel colonoscope. Dig Endosc 2003; 15: 329-332
Bibliography

Dol http://dx.doi.org/ 10.1055/s-0042-115563 Endoscopy 2016; 48: E291-E292

(c) Georg Thieme Verlag KG Stuttgart · New York ISSN 0013-726X

Corresponding author Yoji Takeuchi, MD

Department of Gastrointestinal Oncology Osaka Medical Center for Cancer and Cardiovascular Diseases

1-3-3 Nakamichi, Higashinari-ku Osaka 537-8511

Japan

Fax: +81-6-6981-4067

takeuti-yo@mc.pref.osaka.jp 